\title{
Preface to "Advances in Heterogeneous Catalysis and Electrocatalysis Including New Insights from Surface Science and Quantum Mechanics, Published in Honor of Professor Robert K. Grasselli, Irsee VIII Symposium Kloster Irsee, Germany 23-26 May 2019 (Irsee VIII)"
}

\author{
William A. Goddard III ${ }^{1}$. Douglas J. Buttrey ${ }^{2} \cdot$ Anthony F. Volpe Jr. $^{3}$
}

Accepted: 11 November 2020 / Published online: 19 November 2020

(c) Springer Science+Business Media, LLC, part of Springer Nature 2020
The 8th Irsee Symposium entitled "Advances in Selective Oxidation Catalysis and Electrocatalysis Including New Insights from Surface Science and Quantum Mechanics", sponsored by the Robert Karl Grasselli Foundation, took place at the Schwäbisches Bildungszentrum in Irsee, Germany 23-26 May 2019.

This was a bittersweet gathering honoring the memory and enormous contributions of Robert Karl Grasselli, who died on 11 January 2018. Bob was the inspiration and keystone of these gatherings of selected experts every few years to discuss challenges, opportunities, and new frontiers in catalysis. Marked by critical probing of assumptions and mechanisms by Bob, John Thomas, and others, these meetings continued to invigorate the participants, bringing to bear the experience of the old-timers with the brash new ideas and directions of newcomers at each meeting.

The leadership by Eva-Maria Hauck-Grasselli in making sure this meeting would take place, together with the organizational efforts by Tony Volpe were essential in making it happen, as was the support by the Robert Karl Grasselli

William A. Goddard III

dbuttrey@udel.edu

Douglas J. Buttrey

wag@caltech.edu

Anthony F. Volpe Jr.

Tony.Volpe@clariant.com

1 Caltech, Division of Chemistry and Chemical Engineering, 1200 E California Blvd, Pasadena, CA 91125, USA

2 Center for Catalytic Science and Technology, Department of Chemical and Biomolecular Engineering, Colburn Laboratory, University of Delaware, Room 326, Newark, DE 19716, USA

3 Clariant, 3350 West Bayshore Road, Palo Alto, CA 94303, USA
Foundation. Tony Volpe and Hajo Freund took charge of arranging for the proceedings to be published in Topics in Catalysis.

Many of the speakers addressed the impact that Bob had on their scientific studies in particular and on the field of catalysis in general. This was led off by Doug Buttrey with Reflections on the Life and Contributions of Robert Karl Grasselli, while Ferruccio Trifirò summarized common work with Bob on selective oxidation catalysis.

Newcomers for this eighth Irsee Symposium were Timo Jacob, Marc Koper, Annette Trunschke, Harold H. Kung, Gianfranco Pacchioni, Unni Olsbye, Laura Gagliardi, Vincente Cortés Corberán, and Miguel A. Banares.

Hajo Freund and Joachim Sauer discussed advances in fundamental studies of surface processes and $\mathrm{C}-\mathrm{H}$ bond activation by metal oxides.

Bill Goddard presented a full QM description of the mechanisms for Haber-Bosch synthesis of $\mathrm{NH}_{3}$ combined with in silico search for new optimum catalysts. In addition, he described recent advances in predicting turn-overfrequencies as a function of applied fields for electrocatalytic reduction of $\mathrm{CO}$ to hydrocarbons.

Günther Rupprechter described heterogeneous surfaces as model catalysts, while Annette Trunschke emphasized clean data in oxidation catalysis.

Harold Kung examined perimeter sites for selective oxidation. Anne Gaffney made recommendations on oxidative coupling of methane and Unni Olsbye described the chemical looping approach for selective partial oxidation of methane. Johannes Lercher emphasized chemical and structural aspects of oxidative alkane $\mathrm{C}-\mathrm{H}$ bond activation.

Timo Jacob described advanced fundamental electrochemistry toward energy research while Marc Koper described mechanisms of electrocatalytic hydrogenation and hydrogenolysis, and Costas Vayenas described the role 
of the promoting ionic species in metal-support interactions and electrochemical promotion.

Ive Hermans introduced boron-based materials for the oxidative dehydrogenation of alkanes, while Gerhard Mestl advocated oxidative dehydrogenation of ethane for ethylene production, and Jose López Nieto discussed ethane oxidative dehydrogenation over mixed metal oxides.

Gianfranco Pacchioni described the role of nanostructuring at metal/oxide interfaces for oxidation reactions. Philippe Vernoux showed how dynamic metal support interfaces could enhance catalytic performance of exhaust gas catalysts.
Laura Gagliardi explained hydroxylation of light alkanes by iron-oxo species. Vicente Cortés Corberán examined the role of oxygen in inverse water-gas-shift catalysts. Miguel Bañares showed how operando Raman and IR studies explain ceria-based catalysts for toluene remediation.

Experts representing eight nations participated in this symposium at Kloster Irsee, Germany. We warmly thank all of our participants for joining us and for their contributions to the free exchange of ideas during the meeting. This experience was enriching for all involved and the substance of the contributions is now shared in this special issue of Topics in Catalysis.

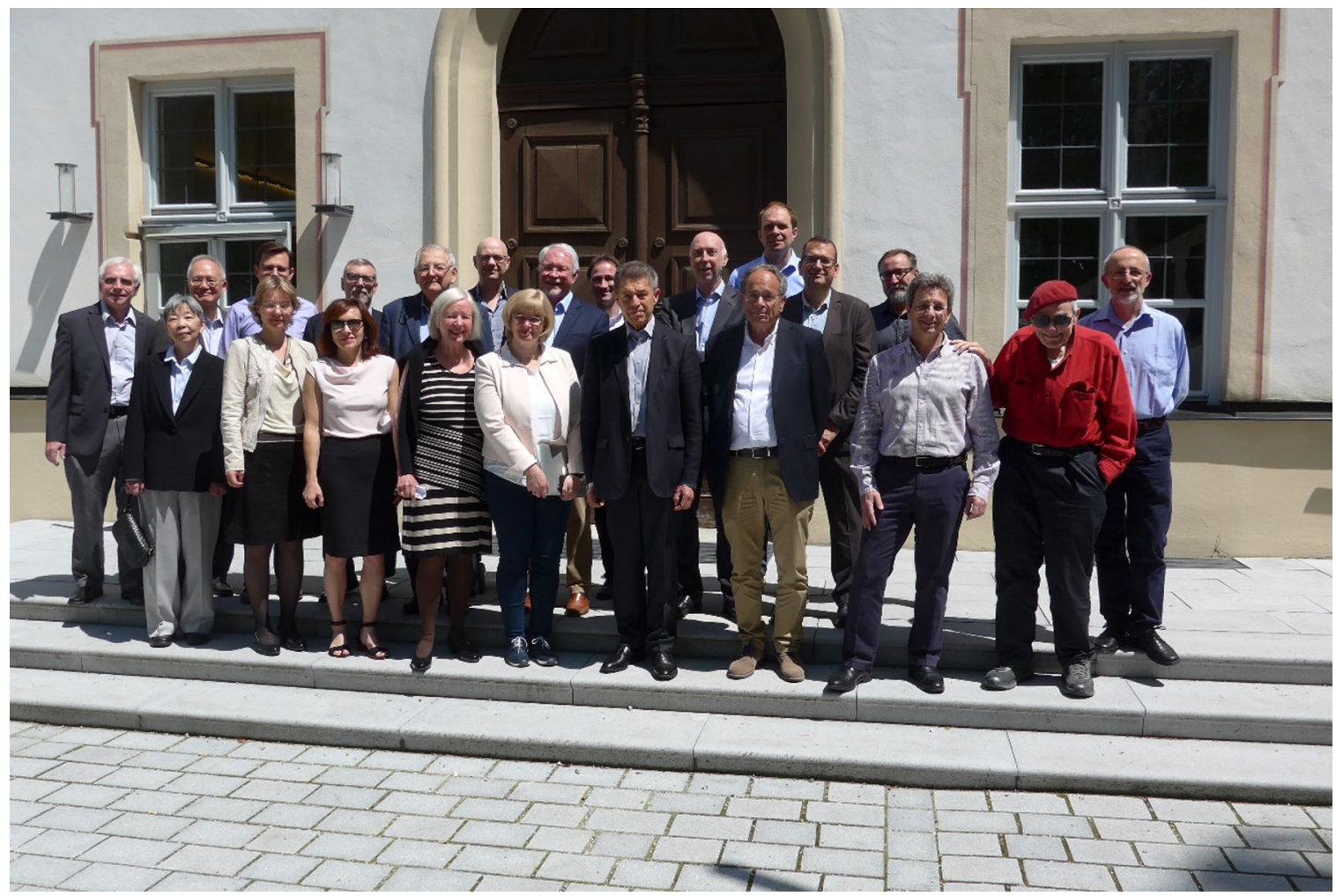

Publisher's Note Springer Nature remains neutral with regard to jurisdictional claims in published maps and institutional affiliations. 